\title{
Prevalence of Autoimmune Thyroid Markers in Euthyroid Women With Polycystic Ovary syndrome
}

Assessment of Autoimmune Thyroid Markers in Euthyroid Egyptian Patients with Polycystic Ovary Syndrome

${ }^{1}$ Ahmed Mohamed Bahaa El-din, ${ }^{1}$ Alyaa Ahmed El-Sherbeny, ${ }^{1}$ Emad Abd El-mohsen Abd El-hadi, ${ }^{1}$ Hesham Abouellail and ${ }^{2}$ Manal Mohsen

${ }^{1}$ Internal Medicine, Faculty of Medicine, Ain Shams University, Egypt

${ }^{2}$ Clinical Pathology, Faculty of Medicine, Ain Shams University, Egypt

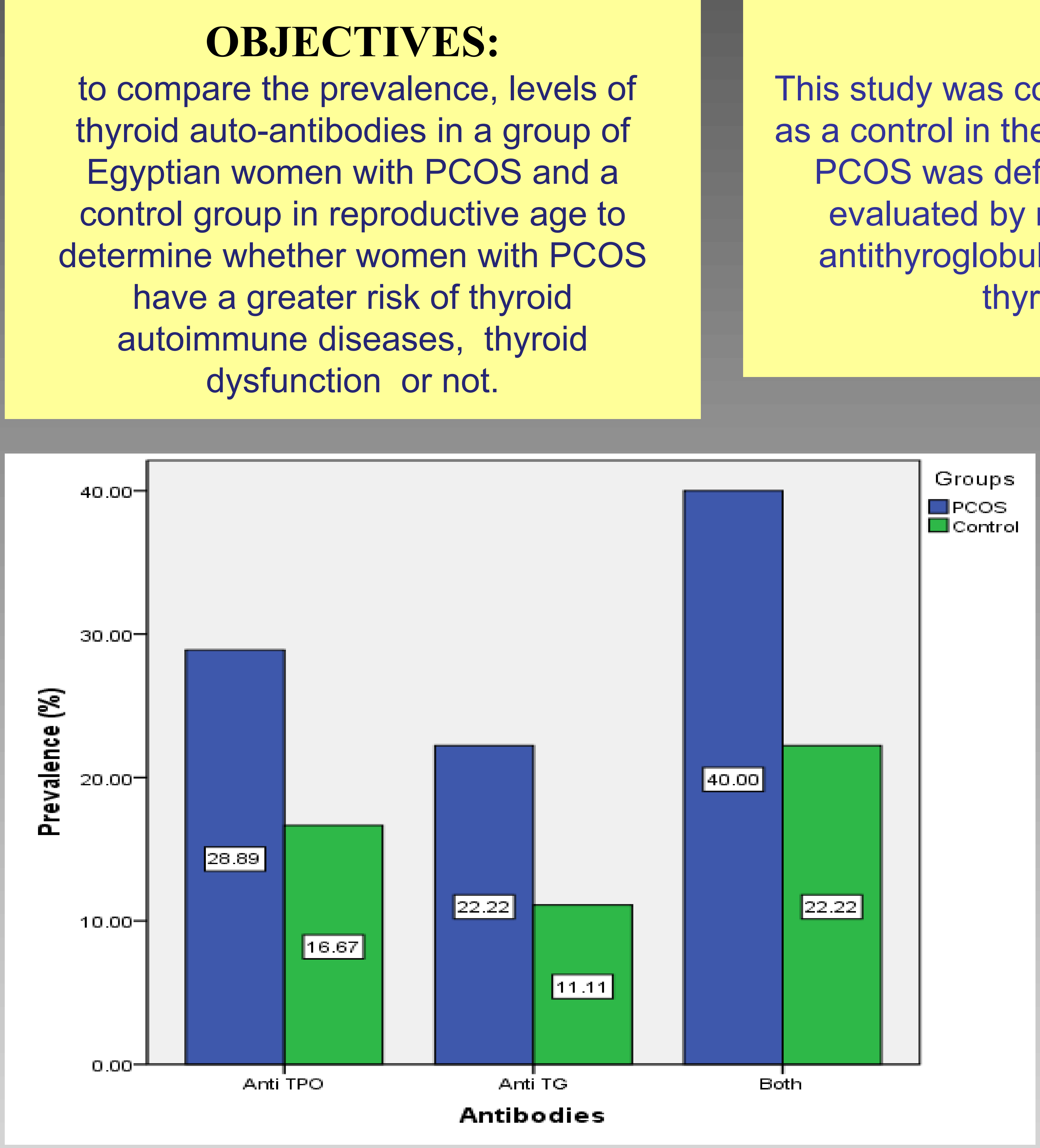

\section{CONCLUSIONS}

This study shows that PCOS was associated with presence of positive thyroid auto-antibodies in the sera of Egyptian patients; so that, these patients could be at increased risk of thyroid disorders

(and fetal loss?). Thyroid autoimmunity markers should be requested in patients with $\mathrm{PCOS}$ who decide to get pregnant even when there is no evidence of overt thyroid dysfunction

\section{METHODS:} This study was conducted on 45 euthyroid women with PCOS and 18 healthy women

PCOS was defined by the revised 2003 Rotterdam criteria. Thyroid function was evaluated by measurement of TSH and FT4 levels, antithyroid peroxidase and thyroid autoimmunity.All parameters were measured using electrochemiluminescence immunoassay.

\begin{abstract}
RESULTS:
Women with PCOS had significantly higher levels of anti-TPO in comparison to controls $(27 \pm 10$ and $21 \pm 10 \mathrm{lU} / \mathrm{mL}$, respectively; $p<0.05$ ) and no significant difference was found in serum levels of anti-TG, TSH, or FT4 between the two groups. Patients with PCOS had a non significant higher prevalence of positive results for anti-TG and/or anti-TPO in

comparison to controls ( $40 \%$ and $22.2 \%$, respectively; $p$ $>0.05$ ), anti-TPO alone (28.9\% and $16.7 \%$, respectively; $p>$ $0.05)$ and anti-TG alone $(22.2 \%$ and $11.1 \%$, respectively; $p>$

$0.05)$. No significant associations were found between the assayed antibodies and thyroid hormones.
\end{abstract}

\section{REFERENCES:}

Azziz R, Carmina E, Dewailly D, Diamanti-Kandarakis E, Escobar-Morreale HF, Futterweit W, et al. The Androgen Excess and PCOS Society criteria for the polycystic ovary syndrome: the complete task force report. FertilSteril. Feb 2009;91(2):456-88.

Barber TM, Franks S, Genetic basis of polycystic ovary syndrome. Expert Rev EndocrinolMetab. 2010;5(4):549-61

Barber TM, McCarthy MI, Wass JA, Franks S. Obesity and polycystic ovary

syndrome. ClinEndocrinol (Oxf). Aug 2006;65(2):137-45.

Gerasimos E. Krassas, PetrosPerros, AthinaKapraraThyroid Autoimmunity, Infertility and Miscarriage.Expert Rev EndocrinolMetab. 2008;3(2):127-136.

Rotterdam EAPCWG. Revised 2003 consensus on diagnostic criteria and long-term health risks related to polycystic ovary syndrome (PCOS). Hum Reprod. 2004;19(1):41-7. Balen AH, Laven JS, Tan SL, Dewailly D. Ultrasound assessment of the polycystic ovary: international consensus definitions. Hum Reprod Update. 2003;9(6):505-14. Petrikova J, Lazurova I, Yehuda S. Polycystic ovary syndrome and autoimmunity. Eur J Intern Med.2010;21(5):369-71. doi: 10.1016/j.ejim.2010.06.008.

Escobar-Morreale HF, Luque-Ramirez M, Gonzalez F. Circulating inflammatory markers in polycystic ovary syndrome: a systematic review and metaanalysis. FertilSteril. 2011;95(3):104858 e1-2. doi: 10.1016/j.fertnstert.2010.11.036.

Hefler-Frischmuth K, Walch K, Huebl W, BaumuehIner K, Tempfer C, Hefler L. Serologic markers of autoimmunity in women with polycystic ovary syndrome. FertilSteril. 2010;93(7):2291-4. doi: 10.1016/j.fertnstert.2009.01.056.

Janssen OE, Mehlmauer N, Hahn S, Offner AH, Gartner R. High prevalence of autoimmune thyroiditis in patients with polycystic ovary syndrome. Eur J Endocrinol. 2004;150(3):363-9. Sinha U, Sinharay K, Saha S, Longkumer TA, Baul SN, Pal SK. Thyroid disorders in polycystic ovarian syndrome subjects: A tertiary hospital based cross-sectional study from Eastern ovarian syndrome subjects: A tertiary hospital based cross-sectional study from Eastern
India. Indian J EndocrinolMetab. 2013;17(2):304-9. doi: 10.4103/2230-8210.109714. Ozdemir D, Cuhaci N, Balkan F, Usluogullari A, Ersoy R, Cakir B. Prevalence of thyroid Ozdemir D, Cuhaci N, Balkan F, Usluogullari A, Ersoy R, Cakir B. Prevalence of thyic
pathologies in patients with polycystic ovary syndrome. EndocrAbstr. 2011;26:92. pathologies in patients with polycystic ovary syndrome. EndocrAbstr. 2011;26:92. women withpolycystic ovary syndrome: A case-control study from Syria.Int J EndocrinolMetab. Ju 2014; 12(3): e17954.doi: 10.5812/ijem.17954.

Kachuei M, Jafari F, Kachuei A, Keshteli AH. Prevalence of autoimmune thyroiditis in patients with polycystic ovary syndrome. Arch Gynecol Obstet. 2012;285(3):853-6. doi: 10.1007/s00404-0112040-5.

Du D, Li X. The relationship between thyroiditis and polycystic ovary syndrome: a meta-analysis. Int J ClinExp Med. 2013 Oct 25; 6(10):880-9.

Ott J, Aust S, Kurz C, Nouri K, Wirth S, Huber JC, Mayerhofer K. Elevated antithyroid peroxidase antibodies indicating Hashimoto's thyroiditis are associated with the treatment response in infertile women with polycystic ovary syndrome. FertilSteril. 2010 Dec;94(7):2895-7. 